\title{
To Evaluate the Shear Bond Strength of Bondable Molar Tubes by Two Enamel Conditioning Techniques
}

\author{
Chanamallappa Ganiger ${ }^{1}$, Nidhi Agarwal ${ }^{2}$, Renuka Pawar ${ }^{3}$, Sandesh Phaphe ${ }^{4}$, Yusuf Ahammed ${ }^{5}$, \\ Pratap Mane ${ }^{6}$, Sahil Patil7, Tanuja Sathe ${ }^{8}$
}

\begin{abstract}
${ }^{1}$ Department of Orthodontics and Dentofacial Orthopaedics, School of Dental sciences, Krishna Institute of Medical Sciences, Malkapaur, Karad, Maharashtra, India. ${ }^{2}$ Department of Orthodontics and Dentofacial Orthopaedics, School of Dental sciences, Krishna Institute of Medical Sciences, Malkapaur, Karad, Maharashtra, India. ${ }^{3}$ Department of Orthodontics and Dentofacial Orthopaedics, School of Dental sciences, Krishna Institute of Medical Sciences, Malkapaur, Karad, Maharashtra, India. ${ }^{4}$ Department of Orthodontics and Dentofacial Orthopaedics, School of Dental sciences, Krishna Institute of Medical Sciences, Malkapaur, Karad, Maharashtra, India. ${ }_{5}^{5}$ Department of Orthodontics and Dentofacial Orthopaedics, School of Dental sciences, Krishna Institute of Medical Sciences, Malkapaur, Karad, Maharashtra, India. ${ }^{6}$ Department of Orthodontics and Dentofacial Orthopaedics,

School of Dental sciences, Krishna Institute of Medical Sciences, Malkapaur, Karad, Maharashtra, India.

${ }^{7}$ Department of Orthodontics and Dentofacial Orthopaedics, School of Dental sciences, Krishna Institute of Medical Sciences, Malkapaur, Karad, Maharashtra, India. ${ }^{8}$ Department of Orthodontics and Dentofacial Orthopaedics,

School of Dental sciences, Krishna Institute of Medical Sciences, Malkapaur, Karad, Maharashtra, India.
\end{abstract}

\section{ABSTRACT}

\section{BACKGROUND}

Shear Bond Strength (SBS) is considered to be the main factor in the evolution of bonding. The bracket bond strength should withstand the forces during the orthodontic tooth movement. The commonly used technique by Orthodontists is to attach the brackets to the enamel surface is the acid-etch bonding technique along with $37 \%$ phosphoric acid as etchant. With time, a new technique emerged in orthodontics which is used before bonding for the primary preparation of teeth as well as for the purpose of increasing bond strength known as Sandblasting. This study was done to compare the shear bond strength of acid etching and air abrasion technique used in orthodontic practice.

\section{METHODS}

A total of 100 extracted human first molar teeth were selected and segregated into 4 groups of 25 teeth. Group I: bonding without enamel preparation, Group II: using acid etching with $37 \%$ phosphoric acid, Group III - sandblasting with $50 \mu$ aluminium oxide, Group IV - sandblasting with $100 \mu$ aluminium oxide. These 100 samples were then subjected to the measurement of the shear bond strength with an Instron machine and was measured in Newtons.

\section{RESULTS}

Group 1 showed a mean shear bond strength of 7.21 \pm 0.29 ; for group II it was $7.77 \pm$ 0.53 ; for group III it was $8.3 \pm 0.3$ and for group IV it was $10.04 \pm 0.45$. Groups 2 and 3 and groups 2 and 4 showed statistically significant difference. Shear bond strengths of both the groups 3 and 4 showed highly statistically significant difference.

\section{CONCLUSIONS}

$100 \mu$ aluminium oxide group showed the highest Shear Bond Strength. On inter group comparison, sandblasting with aluminium oxide was found to have better shear bond strength compared to conventional acid etching techniques.

\author{
Corresponding Author: \\ Dr. Nidhi Agarwal. \\ Department of Orthodontics \\ and Dentofacial Orthopaedics, \\ School of Dental sciences, \\ Krishna Institute of Medical Sciences, \\ Malkapaur, Karad - 415510, \\ Maharashtra, India. \\ E-mail:drnidhi006@gmail.com
}

DOI: $10.14260 /$ jemds/2020/545

How to Cite This Article:

Ganiger C, Agarwal N, Pawar R, et al. To evaluate the shear bond strength of bondable molar tubes by two enamel conditioning techniques. J Evolution Med Dent Sci 2020;9(35):2507-2510, DOI: $10.14260 /$ jemds/2020/545

Submission 13-05-2020,

Peer Review 21-07-2020,

Acceptance 27-07-2020,

Published 31-08-2020.

Copyright (C) 2020 JEMDS. This is an open access article distributed under Creative Commons Attribution License [Attribution 4.0 International (CC BY 4.0)]

\section{KEY WORDS}

Etching, Sandblasting, Bonding, Shear Bond Strength 


\section{BACKGROUND}

To create better facial aesthetics, there is a requirement of an efficient orthodontic treatment. The orthodontist's skills, to properly control the tooth movement during the treatment phase is of utmost importance to successfully bring about the desired result. For the effective movement of the teeth, the interface between the bracket and therefore the wire is taken into consideration. ${ }^{1}$

For over 50 years, the tradition of bonding of orthodontic attachments to enamel has been followed. Bowen introduced dental bonding after Buonocore et al did a pioneering work on enamel preparation techniques. ${ }^{1}$ There has been a lot of progress seen in the field of bonding prioritizing on streamlining the process, improving resistance to demineralization and enhancing performance in a moist environment. Bonding of orthodontic brackets to enamel is taken into account as 'state of art'. There is a requirement to bond the brackets to different restorative materials like composite resin, porcelain, amalgam etc.as well as to the enamel surface of the tooth. So, recently there has been an increase in the research fields on the subject matter of increasing the shear bond strength to the surfaces of the composite.

There should be a proper retention phase within bracket base, type of bonding resin or adhesive and the manner of tooth surface preparation for emphasizing the strength of the bond between the bracket and the enamel surface.The Shear bond Strength (SBS) is considered to be the main factor in the evolution of bonding. The bracket bond strength should withstand the forces during the orthodontic tooth movement. Type of etching, bracket design and size, adhesives, fluorosis, salivary $\mathrm{pH}$, anatomical changes within the teeth surface, masticatory forces, properties of the brackets, technique of the operator, behaviour of the patient and miscellaneous alternative factors have made an intended impression on the orthodontic brackets' shear bond strength.

The commonly used technique by Orthodontists for the bonding of the brackets to the enamel surface is the acid - etch bonding technique. For a composite resin adhesive, manufactures recommend phosphoric acid as an etchant. There is a protocol for the usage of phosphoric acid etching that is it requires rinsing as well as drying of the etchant once it is applied to the tooth surface. There should be proper isolation protocol maintained during the etching as well as the priming procedure. Any contamination throughout this procedure will cause failure of the bond strength of the brackets. Saliva, blood and alternative factors will act as contaminants. Thus utmost care ought to be taken in gingivitis, hyper salivating patients. The favourable outcomes of the sandblasting technique currently used in the field of orthodontics, as well as in other fields of dentistry, suggests a new technique emerged in orthodontics which is used before bonding for the primary preparation of teeth as well as for increasing bond strength. Studies done by Falter Meier and Behr showed that sandblasting improved the shear bond strength (SBS) of stainless steel brackets. ${ }^{2}$ Long span of treatment duration, inapt expenses, inconvenience of the patient, destruction of the enamel layer on debonding at the cessation of the treatment are the issues which arise during the orthodontic treatment because of failure of the bond strength of the brackets. The purpose of this study was to compare the shear bond strength of acid etching and air abrasion technique used in orthodontic practice.

\section{METHODS}

The study was conducted in the Department of Orthodontics and Dentofacial Orthopaedics, KIMSDU, Karad, Maharashtra, India. Ethical clearance was obtained from the university. The study was an experimental randomized control trial. It consisted of a hundred sound (maxillary and mandibular) extracted molar first teeth which were divided into 4 groups of 25 each by using random stratified sampling technique. Pumicing of the extracted teeth using rubber cup with fluoride - free paste for the purpose of cleaning of teeth for a period of $10 \mathrm{sec}$ followed by a water wash and air drying was carried out. To avoid any deterioration, distilled water was used for the placement of extracted teeth, and the water was changed every 24 hours. Morphologically well - defined teeth with no caries, fractures, restorations or structural defects were included in the study. ${ }^{3}$

\section{Sample Size}

Level of significance $=5 \%$, Power $-80 \%$, Type of test $=$ two sided. Formula for calculating sample size for clinical trial (outcome variable on ration scale and testing null hypothesis $\mathrm{M} 1=\mathrm{M} 2=\mathrm{M} 3=\mathrm{M} 4$ (means of four intervention)

$\mathrm{n}=2 \frac{\mathrm{S}^{2}(\mathrm{Z} 1+\mathrm{Z} 2)^{2}}{(\mathrm{M} 1-\mathrm{M} 2)^{2}}$

Where, M1 and M2 are means of group with highest difference.

\section{Power Calculation}

F Test - ANOVA - Fixed effects, omnibus. One - Way Analysis A prior computed required sample size.

\section{Input}

Effect size $\mathrm{f}=0.35$ (larger difference).

(derived from Aman Sachdeva et al 2017).

$\alpha$.err prob $=0.05$

Power $(\mathrm{I}-\beta$.err prob $)=0.80$

Number of groups $=4$

\section{Output}

Non centrality parameter $=11.76$

Critical $\mathrm{f}=2.70$

Numerator $\mathrm{df}=3$

Denominator $\mathrm{df}=92$

Total sample size $=96$

Actual power $=0.814$

A power analysis was established by $\mathrm{G}^{*}$ Power, Version 3.01 (Franz Faul Unviersitat, Kiel, Germany). A total sample size of 96 rounded to 100 ( 25 in each group accounting for four 
study group would yield minimum $80 \%$ power to detect significant differences, with effect size of 0.35 and significance level at 0.05 .

\begin{tabular}{|cc|}
\hline Sr. No. & Material \\
1. & 100 maxillary / mandibular molar teeth \\
2. & Molar bondable tubes \\
3. & Transbond XT (3 M Unitek) \\
4. & Transbond XT Adhesive (3 M Unitek) \\
\hline 5. & $37 \%$ phosphoric acid gel \\
6. & $50 \mu$ aluminium oxide \\
\hline 7. & Acrylic blocks curing gun - Bluephase N \\
8. & Microetcher \\
\hline & Table 1. List of Materials Used in the Study \\
\hline
\end{tabular}

Each tooth was mounted in a self - cure acrylic in such a way that the buccal surfaces were exposed and were then segregated into four groups.

Group 1 consisted of 25 samples with the bondable tube were bonded directly with composite on the tooth surface without any enamel preparation. Group 2 consisted of 25 teeth, where the buccal surfaces of these teeth were acid etched with $37 \%$ phosphoric acid gel for a period of 15 seconds. After this, the teeth were then thoroughly rinsed for 3 seconds with water using a syringe, and then compressed air was used for drying it up. The frosty white appearance showed an appreciation for the etching of enamel surfaces of the teeth. Group 3 had 25 samples; these teeth were sandblasted with 50 $\mu$ aluminium oxide in a Microetcher at 80 psi for 5 seconds through a nozzle distance of $10 \mathrm{~mm}$ at a $45^{\circ}$ angle. After the sandblasting procedure was carried out, surfaces were then cleaned with compressed air. There was absence of the etching procedure of enamel. Group 4 had 25 samples were sandblasted with $100 \mu$ aluminium oxide in a Microetcher at 80 psi for 5 seconds through a nozzle distance of $10 \mathrm{~mm}$ at a $45^{\circ}$ angle. After the sandblasting procedure was carried out, surfaces were then cleaned with compressed air. There was absence of the etching procedure of enamel.

On the prepared enamel surfaces, with the help of a brush a thin coating of bonding agent was applied and then it was subjected to cure. Composite was placed on the base of the bondable tube which was then firmly pushed onto the enamel surface. The excess adhesive which was seen was removed with the help of a probe around the bondable tubes. The Middle third of each tooth were bonded with the bondable tubes, and the specimens were then cured. The shear bond strength of all the hundred samples was measured in an Instron machine and was measured in Newton's.

\section{Statistical Analysis}

The collected data was subjected to statistical analysis. One way ANOVA test was carried out. Tukey's Post hoc test was done to determine the inter group comparison. Value of significance was set at $\mathrm{p}<0.001$.

\section{RESULTS}

A one - way ANOVA test was conducted, and it demonstrated that there was a highly significant difference $(p<0.001)$ with respect to the four methods of preparation of the enamel surface as seen in Table 2 .

\begin{tabular}{|c|c|c|c|}
\hline & MEAN & S.D & \begin{tabular}{cc|} 
ANOVA f & P - Value, \\
Test & Significance
\end{tabular} \\
\hline $\begin{array}{c}\text { Group I } \\
\text { (without enamel preparation) }\end{array}$ & 7.21 & 0.29 & \\
\hline $\begin{array}{c}\text { Group II } \\
\text { (Acid etching }-37 \% \text { phosphoric acid) }\end{array}$ & 7.77 & 0.53 & \\
\hline $\begin{array}{c}\text { Group III } \\
\text { (Sand blasting - } 50 \mu \mathrm{Al}_{2} \mathrm{O}_{3} \text { ) }\end{array}$ & 8.3 & 0.3 & $\mathrm{f}=223.87 \quad \mathrm{P}<0.001^{* *}$ \\
\hline $\begin{array}{c}\text { Group IV } \\
\text { (Sand blasting - } 100 \mathrm{\mu} \mathrm{Al}_{2} \mathrm{O}_{3} \text { ) }\end{array}$ & 10.04 & 0.45 & \\
\hline \multicolumn{4}{|c|}{$\begin{array}{c}\text { Table 2. Comparative Statistics of Shear Bond Strength Parameter } \\
\text { of Different Tooth Preparation Techniques Using One Way } \\
\text { ANOVAf - Test }\end{array}$} \\
\hline
\end{tabular}
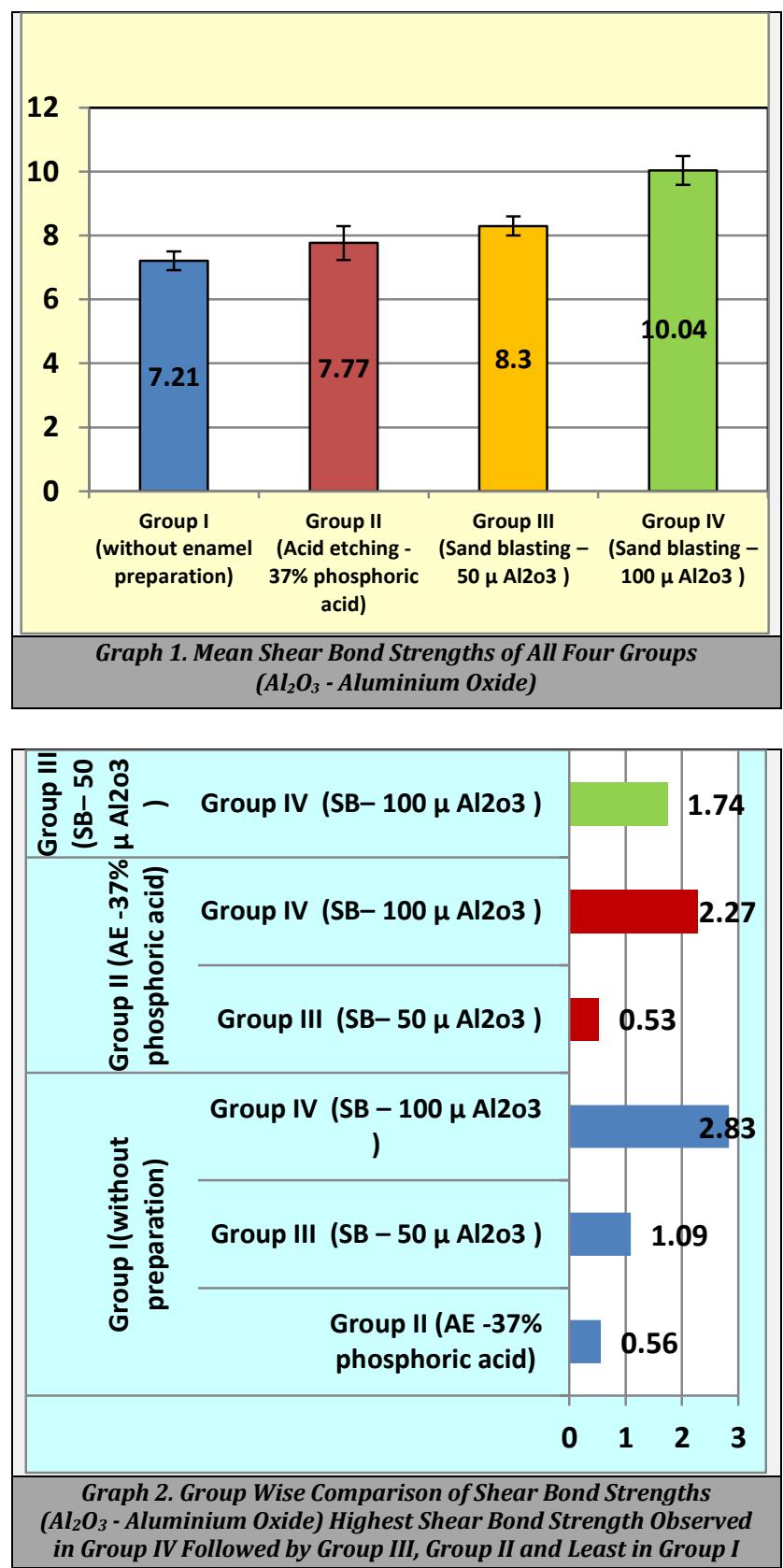

Tukey's post hoc test was applied for inter group comparison. On pair wise comparison between groups pairs, highly significant difference $(\mathrm{p}<0.001)$ exists among each group pair. There was a statistically significant difference between shear bond strengths of groups 2 and 3 and groups 2 
and 4 ( $\mathrm{p}<0.001$.) There was also a highly statistically significant difference in the shear bond strengths of groups 3 and group $4(\mathrm{p}<0.001$.) as seen in graph 2 .

\begin{tabular}{|c|c|c|c|}
\hline Group & Comparison Group & $\begin{array}{c}\text { Mean } \\
\text { Difference }\end{array}$ & $\begin{array}{c}\text { P Value, } \\
\text { Significance }\end{array}$ \\
\hline \multirow{3}{*}{$\begin{array}{l}\text { Group I } \\
\text { (without enamel } \\
\text { preparation) } \\
\text { vs }\end{array}$} & $\begin{array}{c}\text { Group II } \\
\text { (Acid etching }-37 \% \text { phosphoric } \\
\text { acid) }\end{array}$ & 0.56 & $\mathrm{p}<0.001^{* *}$ \\
\hline & $\begin{array}{c}\text { Group III } \\
\text { (Sand blasting - } 50 \mu \mathrm{Al}_{2} \mathrm{O}_{3} \text { ) }\end{array}$ & 1.09 & $\mathrm{p}<0.001^{* *}$ \\
\hline & $\begin{array}{c}\text { Group IV } \\
\text { (Sand blasting - } 100 \mu \mathrm{Al}_{2} \mathrm{O}_{3} \text { ) }\end{array}$ & 2.83 & $\mathrm{p}<0.001^{* *}$ \\
\hline \multirow{3}{*}{$\begin{array}{c}\text { Group II } \\
\text { (Acid etching - } 37 \% \\
\text { phosphoric acid) } \\
\text { vs } \\
\text { Group III } \\
\text { (Sand blasting - } 50 \\
\mu \mathrm{Al}_{2} \mathrm{O}_{3} \text { ) } \\
\text { vs }\end{array}$} & $\begin{array}{c}\text { Group III } \\
\text { (Sand blasting }-50 \mu \mathrm{Al}_{2} \mathrm{O}_{3} \text { ) }\end{array}$ & 0.53 & $\mathrm{p}<0.001^{* *}$ \\
\hline & $\begin{array}{c}\text { Group IV } \\
\text { (Sand blasting - } 100 \mu \mathrm{Al}_{2} \mathrm{O}_{3} \text { ) }\end{array}$ & 2.27 & $\mathrm{p}<0.001^{* *}$ \\
\hline & $\begin{array}{c}\text { Group IV } \\
\text { (Sand blasting - } 100 \mu \mathrm{Al}_{2} \mathrm{O}_{3} \text { ) }\end{array}$ & 1.74 & $\mathrm{p}<0.001^{* *}$ \\
\hline \multicolumn{4}{|c|}{$\begin{array}{c}\text { Table 3. Intergroup Pairwise Comparative Statistics of Shear Bond } \\
\text { Strength Parameter of Different Tooth Preparation Techniques Using } \\
\text { Tukey's Post Hoc Test }\left(\mathrm{Al}_{2} \mathrm{O}_{3} \text { - Aluminium Oxide) }\right.\end{array}$} \\
\hline
\end{tabular}

\section{DISCUSSION}

The advent of enamel preparation technique brought about a radical change in the concept of orthodontic attachment procedure.

The primary intentions of enamel etching were to increase the surface area and thereby change the surface from a low energy hydrophobic surface to high - energy hydrophilic surface. ${ }^{4}$ Modifying the surface characteristic of the enamel for adhesive attachment as the various surface characteristic may be easily accomplished were the principles of Silverstone. 5 There are a lot of techniques emerging in the field of dentistry for orthodontic brackets, namely, orthophosphoric acid, sandblasting, and laser irradiation have been used to etch enamel for orthodontic bonding. Throughout the treatment, the brackets which are bonded to teeth for orthodontic purposes should remain affixed to the teeth.

As seen in table 3 , statistically significant differences were found between acid etch technique, $50 \mu$ particles of aluminium oxide and $100 \mu$ particles of aluminium oxide when compared to a control group. When we compared acid etching technique with $50 \mu$ particles of aluminium oxide and $100 \mu$ particles of aluminium oxide, a mean difference of $0.53 \mathrm{MPa}$ and 2.27 MPa was found respectively (Table 3).

In this study when using $50 \mu$ particles in place of acid etching technique improved the bond strength which was similar with the findings of Canay et al. ${ }^{6}$ But Roeder et al or Brown and Barkmeier, found that there is no significant difference between these groups and their result was inconsistent with the results presented in this study.7,8 However, Nikaido et al. found that the bond strength decreased significantly when using $50 \mathrm{~mm}$ particles compared with no air abrasion. ${ }^{9}$ The present study found statistical difference between air abrasion with $50 \mu$ particles of aluminium oxide and $100 \mu$ particles of aluminium oxide (Table 3). Where $100 \mu$ showed higher bond strength compared to $50 \mu$ particles. These results are in accordance to the study conducted by Halpern et al who concluded that that the strongest method for bonding orthodontic brackets was air abrasion with $100 \mu$ particles of aluminium oxide.

\section{CONCLUSIONS}

The current study showed a highly significant difference between shear bond strengths in all the groups. $100 \mu$ aluminium oxide group showed the highest Shear Bond Strength. On inter group comparison, sandblasting with aluminium oxide was found to have better shear bond strength compared to conventional acid etching techniques.

Financial or Other Competing Interests: None.

\section{REFERENCES}

[1] Suma S, Anita G, Chandra Shekar BR, et al. The effect of air abrasion on the retention of metallic brackets bonded to fluorosed enamel surface. Indian $J$ Dent Res 2012;23(2):230-5.

[2] Faltermeier A, Behr M. Effect of bracket base conditioning. Am J Orthod Dentofacial Orthop 2009;135(1):12.e1-5.

[3] Sachdeva A, Raghav S, Goel M, et al. A comparison of the shear bond strength of conventional acid etching, selfetching primer, and single bottle self- adhesive - an in vitro study. Indian J Dent Sci 2017;9(3):170-5.

[4] Reynolds IR. A review of direct orthodontic bonding. British Journal of Orthodontics 1975;2(3):171-8.

[5] Silverstone LM, Saxton CA, Dogan IL, et al. Variation in the pattern of acid etching on human dental enamel examined by scanning electron microscope. Caries Res 1975;9(5):373-87.

[6] Canay S, Kocadereli I, Akşa E. The effect of enamel air abrasion on the retention of bonded metallic orthodontic brackets. Am J Orthod Dentofacial Orthop 2000;117(1):15-9.

[7] Roeder LB, Berry EA, You C, et al. Bond strength of composite to air-abraded enamel and dentin. Oper Dent 1995;20(5):186-90.

[8] Brown JR, Barkmeier WW. A comparison of six enamel treatment procedures for sealant bonding. Pediatr Dent 1996;18(1):29-31.

[9] Nikaido T, Kataumi M, Burrow MF, et al. Bond strengths of resin to enamel and dentin treated with low-pressure air abrasion. Oper Dent 1996;21(5):218-24. 